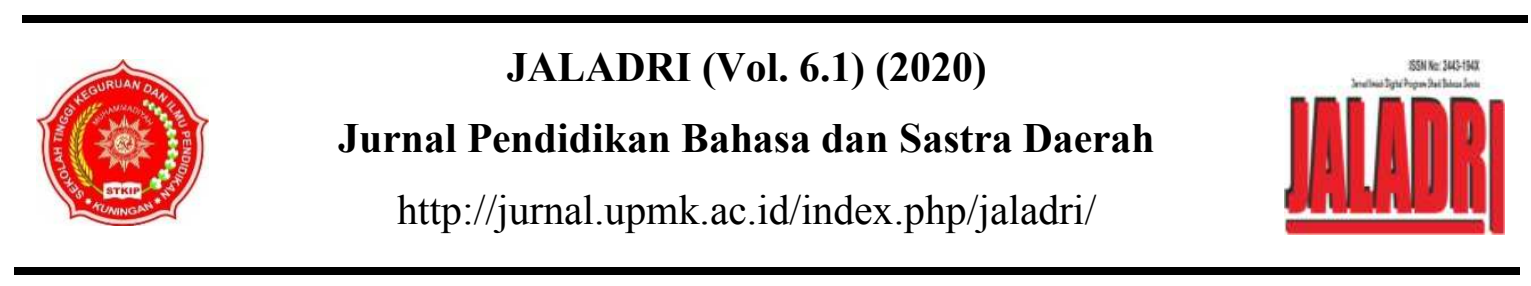

\title{
KAPAMALIAN DI KASEPUHAN CIPTAGELAR
}

Dewi Rahayu, Hana Rabiatul A, Imas Siti Fatimah, Nuke Virginia Yuanto

dewirahayu02@student.upi.edu

Departemen Pendidikan Bahasa Sunda

Universitas Pendidikan Indonesia

\section{Info Artikel}

Sejarah Artikel:

Diterima : 10 Januari 2020

Disetujui : 10 April 2020

Dipublikasikan : 25 April 2020

Kata Kunci:

Pamali;

kapamalian;

hukum adat;

Kasepuhan

Ciptagelar.

\section{Abstrak}

Penelitian ini dilatarbelakangi oleh keunikan pengamalan pamali di Kasepuhan Ciptagelar Kabupaten Sukabumi. Kajian ini merupakan penelitian kualitatif dengan metode deskripstif. Tujuannya untuk mengumpulkan dan mengklasifikasikan pamali yang masih ada di masyarakat Kasepuhan Ciptagelar. Sumber data dalam penelitian ini adalah pamali yang masih dipakai di Kasepuhan Ciptagelar. Teknik yang dipakai dalam penelitian ini adalah teknik wawancara dan teknik observasi langsung. Berdasarkan hasil penelitian didapat 188 pamali yang diklasifikasikan menjadi enam, yaitu (1) jangan memperjualbelikan beras; (2) wanita yang sedang datang bulan tidak diperbolehkan ikut memasak di dapur imah gede; (3) tidak boleh membangun rumah tembok; (4) harus mengenakan iket bagi laki-laki; (5) harus memakai samping bagi perempuan; (6) dilarang berbicara ketika sedang menumbuk padi; (7) jangan memperjualbelikan labu (8) jangan keluar malam dan pergi ke hutan sendirian. Semua kapamalian yang terdapat di Kasepuhan Ciptagelar merupakan salah satu warisan para leluhur secara turun-tumurun yang harus ditaati karena telah termasuk ke dalam hukum adat. Jika seorang masyarakat di Kasepuhan Ciptagelar ada yang melanggar kapamalian tersebut, maka dia akan mendapat hukuman adat dan hukuman terhadap dirinya sendiri dari para leluhur. 
Key Words:

Pamali;

kapamalian; customary law;

Kasepuhan

Ciptagelar.
This research is motivated by the uniqueness ofpractices pamali in Kasepuhan Ciptagelar, Sukabumi Regency. This study is a qualitative research with descriptive method. The aim is to collect and classify the pamali that still exist in the Kasepuhan Ciptagelar community. The data source in this study is Pamali which is still used in Kasepuhan Ciptagelar. The techniques used in this study are interview techniques and direct observation techniques. Based on the research results obtained 188 pamali which are classified into six, namely (1) do not trade rice; (2) women who are menstruating are not allowed to participate in cooking in thekitchen big imah; (3) may not build a wall house; (4) must wear iket for men; (5) must wear the side for women; (6) speaking is prohibited when pounding rice; (7) don't trade pumpkins (8) don't go out at night and go to the forest alone. All capamalian found in Kasepuhan Ciptagelar is one of the inheritance of the ancestors which must be obeyed because it is included in customary law. If a community member in Kasepuhan Ciptagelar violates the kapamalian, he will get adat punishment and punishment for himself from the ancestors. 


\section{PENDAHULUAN}

Indonesia sangat kaya dengan adat dan budayanya. Hal ini terlihat di antaranya dari banyaknya kearifan lokal yang tersebar di wilayah negara ini, termasuk di masyarakat Sunda. Kearifan lokal inilah yang menurut Suherman (2018: 109) dapat membentuk karakter manusia Sunda menjadi manusa yang cageur,bageur, bener, pinter, dan singer, yang senantiasa mengamalkan silih asah, silih asih, dan silih asuh. Hasil dari pengamalan nilai-nilai tersebut akan membentuk manusia Sunda yang seimbang antara lahir dan batinnya atau manusia yang sempurna (manusa manggapulia).

Demikian juga dengan sumber daya alam yang sangat melimpah-ruah yang selalu dimanfaatkan oleh tangan-tangan kreatif menjadi sebuah karya, baik yang bersifat benda fungsional maupun sebagai benda pajang (hiasan), dengan kata lain kriya selalu berkaitan dengan kearifan lokal dan kebudayaan. Kebudayaan pada dasarnya merupakan segala macam bentuk gejala kemanusiaan, baik yang mengacu pada sikap, konsepsi, ideologi, prilaku, kebiasaan, karya kreaitf, dan sebagainya. Secara kongkret kebudayaan bisa mengacu pada adat istiadat, bentuk-bentuk tradisi lisan, karya seni, bahasa, pola interaksi, dan sebagainya. Dengan kata lain, kebudayaan merupakan fakta kompleks yang selain memiliki kekhasan pada batas tertentu juga yang bersifat universal (Maryaeni, 2005: 5).

Kebudayaan merupakan cara hidup suatu masyarakat. Cara hidup ini didasari oleh adanya pengetahuan bersama yang merupakan sistem gagasan bersama dan bersifat normatif. Gagasan bersama ini merupakan satu kesataun yang bersumber pada gagasan intinya. Gagasan ini tidak nampak (intangible) karena berada dalam kesadaran anggota-anggota masyarakatnya. Gagasan yang merupakan kesatuan cara berpikir ini baru nampak dalam tingkah laku atau perbuatan masyarakatnya. (Sumardjo, 2011: 154).

Menurut Soemardjan dan Soemardi dalam Wulansari (2009: 76) kebudayaan adalah semua hasil karya, rasa, dan cipta masyarakat. Sedangkan menurut Koentjaraningrat (2002:11) kebudayaan adalah segala hal yang dimiliki manusia, yang hanya diperolehnya hanya belajar dan menggunakan akalnya. Manusia dapat berjalan karena kemampuan untuk berjalan itu didorong oleh nalurinya, dan terjadi secara alamiah. Menurut Taylor (dalam
Soelaeman, 2010: 19) Kebudayaan ataupun yang disebut peradaban, mengandung pengertian yang luas, meliputi pemahaman perasaan suatu bangsa yang kompleks, meliputi pengetahuan, kepercayaan, seni, moral, hukum, adat istiadat (kebiasaan), dan pembawaan lainnya yang di peroleh dari anggota masyarakat. Dari beberapa pengertian tersebut dapat disimpulkan bahwa kebudayaan adalah keseluruhan dari kesatuan sistem pengetahuan dan perilaku manusia yang menghasilkan suatu karya dalam sebuah masyarakat, secara tidak langsung yang dijadikan sebagai milik dari masyarakat tersebut.

Dari kebudayaan yang hidup di masyarakat dalam jangka waktu yang lama, membentuk pola dari unsur-unsur kebudayaan di atas. Salah satu produk budayanya yaitu Folklor. Folklor adalah bagian dari budaya yang bersifat lisan. Folklor terbagi menjadi tiga yaitu folklor lisan, folklor setengah lisan dan folklor non-lisan. Folklor yang bersifat lisan sangat erat berkaitan dengan kebudayaan di suku Sunda, hal ini karena tradisi lisan lebih dulu ada dibandingkan tradisi tulis. Keberadaan tradisi lisan di antaranya terbukti dengan adanya karya sastra dan budaya seperti carita pantun, dongeng, mantra, dan pamali. Pembacaan atau apresiasi terhadap karyakarya tersebut dianggap oleh Suherman (2019: 264) sebagai kegiatan literasi budaya, bagian dari literasi dasar.

Kapamalian berasal dari kata pamali. Pamali merupakan hal yang tidak lepas dari kehidupan manusia dan bagian dari kebudayaan yang diciptakan dari hubungan manusis dalam lingkungan sosialnya. Menurut Danadibrata (2009: 489) pamali adalah suatu larangan leluhur yang memiliki maksud dan tujuan untuk tidak melakukan suatu pekerjaan dikarenakan akan mendatangkan musibah.

Dalam kajian ini penulis menjadikan masyarakat Kasepuhan Ciptagelar sebagai sumber data, data yang dihasilkan adalah pamali yang masih diterapkan di masyakat Kasepuhan Ciptagelar, Desa Sirnaresmi, Kecamatan Cisolok, Kabupaten Sukabumi. Penulis memilih Kasepuhan Ciptagelar sebagai objek penelitian dikarenakan pola hidup masyarakatnya yang masih memegang teguh kapamalian, sehingga pamali masih dipakai dalam kehidupanya seharihari. Penelitian ini bertujuan untuk mengumpulkan kapamalian yang masih dipakai oleh masyarakat Kasepuhan Ciptagelar, membuat 
klasifikasi, dan menginterpretasikan pamali yang masih ada.

Kasepuhan Ciptagelar adalah sebuah Kasepuhan adat yang memiliki ciri khas dalam lokasi dan bentuk rumah serta tradisi yang masih dipegang kuat oleh masyarakat pendukungnya. Masyarakat yang tinggal di Kasepuhan Ciptagelar disebut masyarakat kasepuhan. Istilah kasepuhan berasal dari kata sepuh dengan awalan / ka-/ dan akhiran /-an/. Dalam bahasa Sunda, kata sepuh berarti 'kolot' atau 'tua'. Berdasarkan pengertian ini, muncullah istilah kasepuhan, yaitu tempat tinggal para sesepuh. Sebutan kasepuhan ini pun menunjukkan model 'sistem kepemimpinan' dari suatu komunitas atau masyarakat yang berasaskan adat kebiasaan para orang tua (sepuh atau kolot). Kasepuhan berarti 'adat kebiasaan tua' atau 'adat kebiasaan nenek moyang'.

Kasepuhan Ciptagelar adalah salah satu dari tiga kasepuhan yang berada di wilayah Desa Sirnaresmi. Wilayah Kasepuhan Ciptagelar dibagi atas tiga dusun yakni Dusun Sukamulya, Dusun Situmurni dan Dusun Cipulus. Dari tiga dusun ini dibagi lagi ke dalam 16 Kasepuhan (lembur). Secara administratif Kasepuhan Ciptagelar termasuk dalam wilayah Desa Sirnaresmi, Kecamatan Cisolok, Kabupaten Sukabumi, Provinsi Jawa Barat. Masyarakat Kasepuhan Ciptagelar memiliki berbagai kapamalian yang masih hidup dan berkembang di masyarakat tersebut.

\section{METODE PENELITIAN}

Penelitian ini menggunakan metode deskriptif. Berdasarkan judul yang diangkat yaitu "Kapamalian di Kasepuhan Ciptagelar", maka penelitian ini termasuk jenis penelitian naturalistik atau biasa disebut kualitatif. Bogdan dan Taylor (dalam Moleong, 2015: 4) menyatakan bahwa metodologi kualitatif sebagai prosedur penelitian yang menghasilkan data deskritif berupa kata-kata tertulis atau lisan dari orangorang dan perilaku yang dapat diamati. Pendekatan ini diarahkan pada latar dan individu tersebut secara holistik (utuh).

Data diperoleh melalui beberapa proses yaitu observasi, wawancara, dan dokumentasi. Penelitian kualitatif didasarkan pada upaya membangun pandangan yang diteliti secara rinci, dibentuk dengan kata-kata, gambaran holistik dan rumit. Selain itu juga untuk memahami fenomena tentang apa yang dialami oleh subjek penelitian misalnya prilaku, persepsi, motivasi, tindakan dan lain-lain. Secara holistik, dan dengan cara deskriptif dalam bentuk kata-kata dan bahasa, pada suatu konteks khusus yang alamiah dan dengan memanfaatkan berbagai metode alamiah dengan mengutamakan manusia sendiri sebagai instrumennya. Tujuan penelitian ini adalah untuk mengkaji kapamalian yang ada di masyarakat Kasepuhan Ciptagelar.

\section{HASIL DAN PEMBAHASAN}

\section{Adat Kapamalian di Kasepuhan Ciptagelar}

Dari hasil penelitian langsung kepada masyarakat Kasepuhan Ciptagelar, terdapat beberapa kapamalian yang sudah ada atau diwariskan oleh leluhur Kasepuhan Ciptagelar secara turun-temurun. Menurut Satjadibrata (2005) kapamalian adalah palangan, pamali, dan disebut pamali jika sudah dilaksanakan. Kapamalian ini dapat dikategorikan kedalam folklor lisan. Foklor lisan adalah folklor yang bentuknya memang murni lisan. Pernyataan tersebut memiliki makna yaitu folklor yang bersumber dari lisan dan penyebarannya melalui lisan (Danandjaja, 1984: 21).

Pamali yang ditujukan bagi seluruh warga Kasepuhan Ciptagelar di antaranya pertama tidak diperbolehkan memperjualbelikan beras. Hal ini karena adanya kepercayaan masyarakat Kesepuhan Ciptagelar terhadap leluhur dan kepercayaan kepada Dewi Sri. Bagi mereka, Dewi Sri dipercaya sebagai lambing kemakmuran dan kesuburan. Dewi Sri diyakini sosok suci yang mengatur kesejahteraan di bumi. Jadi Dewi Sri atau yang terkenal dengan sebutan Nyi Pohaci adalah berkah hidup masyarakat Pajajaran. Dari kematian Dewi Sri tumbuh kehidupan. Tanpa Dewi Sri, masyarakat Sunda tidak memperoleh kehidupannya. Itulah sebabnya masyarakat adat Kesepuhan Ciptagelar sangat menghormati Dewi Sri sekaligus sangat menghargai padi. Selain itu, padi juga berasal dari tanah dan merupakan bahan pokok atau sumber kehidupan masyarakat Ciptagelar. Sama halnya dengan manusia yang dipercayai berasal dari saripati tanah. Dengan demikian, masyarakat Ciptagelar tidak diperbolehkan memperjualbelikan padi/beras karena itu sama halnya dengan menjual harga diri atau menjual diri sendiri.

Kedia wanita yang sedang datang bulan tidak diperbolehkan ikut memasak di dapur imah gede, karena imah gede merupakan sebuah tempat 
yang sakral bagi masyarakat Kasepuhan Ciptagelar. Selain itu, terdapat beberapa alasan yang diyakini oleh masyarakat Kasepuhan Ciptagelar, apabila memasak dalam keaadaan datang bulan akan berdampak secara langsung pada hasil masakannya. Seperti pada saat menanak nasi, nasi yang dibuat akan lembek dan juga berwarna merah. Untuk tamu atau pendatang dari luar Kasepuhan Ciptagelar, hal ini merupakan hal yang mustahil untuk dipercaya. Namun, untuk masyarakat Kasepuhan Ciptagelar sendiri ini merupakan hal yang faktual dan pernah terjadi, baik secara implisit maupun eksplisit hasilnya akan terlihat.

Ketiga jangan membangun rumah tembok. Jenis kapamalian ini berhubungan dengan adanya bencana alam yaitu gempa bumi. Masyarakat Kasepuhan Ciptagelar percaya bahwa kapamlian ini merupakan bentuk kasih sayang para leluhur pada generasinya agar terhindar dari bencana alam yaitu gempa bumi. Seperti diketahui bahwa rumah bilik atau rumah yang terbuat dari kayu tanpa menggunakan batu bata atau tembok, sangat aman dan tidak mudah roboh ketika adanya gempa bumi. Selain itu, Kasepuhan Ciptagelar berada di atas Gunung Halimun yang keadaanya dingin, maka rumah bilik sangat cocok digunakan untuk kondisi tersebut.

Keempat harus memakai iket bagi lakilaki. Iket merupakan jenis penutup kepala yang terbuat dari kain dan dipakai dengan teknik tertentu seperti dilipat, dilipit, dan disimpulkan sebagai pengikat akhir. Bagi masyarakat Kasepuhan Ciptagelar diyakini bahwa ketika memasuki kawasan imah gede harus menggunakan iket. Hal ini berhubungan dengan kebiasaan para leluhur sejak dahulu, yang memiliki maksud bahwa iket itu sebagai pengikat atau penghubung persaudaraan, juga merupakan ciri khas bagi kaum laki-laki Sunda. Selain itu, iket juga memiliki fungsi sebagai pelindung kepala agar terhindar dari panas. Namun hal ini tidak berlaku untuk tamu atau pendatang, walaupun demikian, alangkah lebih eloknya jika tamu pun mengenakannya untuk menghargai etika di imah gede.

Kelima perempuan harus memakai samping. Kasepuhan Ciptagelar merupakan masarakat Sunda yang masih memegang adat dengan teguh dalam kehidupan sehari-hari. Maka dari itu, tidak heran jika di Kasepuhan Ciptagelar para perempuan masih menggunakan pakaian adat dan peralatan tradisional. Perempuan Sunda jaman dahulu dalam kehidupan sehari-harinya sering menggunakan samping sebagai penutup aurat. Kebiasaan menggunakan samping tersebut masih berlaku di Kasepuhan Ciptagelar sebagai adat berpakaian. Selain sebagai masyarakat yang memegang teguh adat Sunda, bagi masyarakat Kasepuhan Ciptagelar samping juga diyakini dapat melindungi diri perempuan dari hal-hal yang dapat menimbulkan musibah. Namun, hal ini tidak berlaku untuk tamu atau pendatang, walau pun demikian, berkaitan dengan etika yang ada di imah gede maka alangkah lebih baik jika tamu perempuan mengenakan samping juga, sebagai bentuk penghormatan dan ciri khas perempuan Sunda.

Keenam dilarang berbicara ketika sedang menumbuk padi. Masyarakat Kasepuhan Ciptagelar merupakan masyarakat yang menjungjung tinggi norma dan etika. Hal ini berkaitan dengan kebiasaan atau tradisi dalam menumbuk padi. Menumbuk padi di Kasepuhan Ciptagelar berbeda dengan menumbuk padi di kampung adat lainnya. Di Kasepuhan Ciptagelar untuk menumbuk padi harus disediakan lesung yang dibuat di hutan. Selain itu, dalam menumbuk padi juga sering diiringi oleh kesenian angklung dogdog lojor. Menumbuk padi termasuk dalam kegiatan sakral karena erat kaitannya dengan Dewi Sri atau Dewi Padi. Alasan dilarang berbicara ketika menumbuk padi sebagai bentuk penghormatan kepada Dewi Sri, selain itu juga agar lebih bisa memaknai apa yang terkandung dalam isi lagu yang dilantunkan dalam kesenian angklung dogdog lojor.

Ketujuh dilarang memperjualbelikan labu dan singkong. Hal ini disebabkan karena labu dan singkong seringkali dijadikan pengganti nasi sekaligus merupakan bahan pembuatan kerupuk atau masakan lainnya. Selain itu, labu dan singkong juga ditanam di tanah seperti halnya padi. Masyarakat Ciptagelar meyakini bahwa nasi merupakan kebutuhan pokok dan dilarang untuk diperjualbelikan sama halnya dengan labu dan singkong yang juga merupakan bahan pokok.

Kedelapan jangan keluar malam dan pergi ke hutan sendirian. Hal ini berhubungan dengan masyarakat Sunda pada jaman dahulu yang mempercayai bahwa ketika adzan magrib berkumandang, sandekala atau misteri Sunda yang dianggap monster akan bermunculan ke bumi dan bisa menggangu manusia. Monster 
Sunda tersebut telah lama dituturkan secara turun-temurun oleh para leluhur. Masyarakat Kasepuhan Ciptagelar percaya bahwa sandekala ini bisa mengganggu manusia dan membawa pergi atau menyembunyikan manusia pada malam hari. Jika ditelusuri lebih lanjut, hal ini juga berhubungan dengan keadaan maghrib yang gelap yang dapat membuat penglihatan manusia berkurang, selain itu pada zaman dahulu belum ada listrik yang mengakibatkan banyak orang hilang ketika malam hari karena gelap dan tersasar. Sedangkan pergi ke hutan sendirian sebenarnya merupakan bentuk kepercayaan masyarakat Kasepuhan Ciptagelar yang berhubungan dengan ketakutan akan terjadi halhal yang tidak terduga, yang dapat menyelakakan diri, sehingga jika pergi ke hutan lebih baik berdua terutama pada malam hari.

\section{KESIMPULAN}

Kapamalian dapat dikategorikan sebagai folklor lisan. Simpulan yang dapat diambil dari hasil penelitian langsung kepada masyarakat Kasepuhan Ciptagelar yaitu terdapat beberapa kapamalian yang sudah ada serta terus diwariskan secara turun-temurun. Sampai saat ini masyarakat Kasepuhan Ciptagelar masih memegang teguh keyakinan terhadap adat kapamalian. Berdasarkan klasifikasinya, pamali di Kasepuhan Ciptagelar terbagi menjadi enam, yaitu (1) Jangan memperjualbelikan beras. Hal ini karena adanya kepercayaan masyarakat kesepuhan Ciptagelar terhadap karuhun serta kepercayaan kepada Dewi Sri, sebagai lambang kemakmuran dan kesuburan. (2) Wanita yang sedang datang bulan tidak diperbolehkan ikut memasak di dapur imah gedé, karena imah gede merupakan tempat yang sakral bagi masyarakat Kasepuhan Ciptagelar dan jika dilanggar akan berdampak secara langsung pada hasil masakannya. (3) Jangan membangun rumah tembok. Masyarakat Kasepuhan Ciptagelar percaya bahwa kapamalian ini merupakan bentuk kasih sayang para leluhur agar terhindar dari bencana, karena rumah bilik sangat aman dan tidak mudah roboh ketika terjadi gempa bumi. (4) Laki-laki harus memakai iket. Masyarakat Kasepuhan Ciptagelar meyakini bahwa iket merupakan pengikat dan melambangkan persaudaraan. Oleh sebab itu, sangat dianjurkan jika memasuki kawasan imah gede mengenakan iket. (5) Peremuan haru memakai samping. Perempuan Sunda jaman dahulu dalam kehidupan sehari-harinya sering menggunakan samping sebagai penutup aurat. Bagi masyarakat
Kasepuhan Ciptagelar mengenakan samping juga diyakini dapat melindungi perempuan dari halhal yang dapat menimbulkan musibah. (6) Dilarang berbicara ketika menumbuk padi. Hal ini sebagai perwujudan etika terhadap Dewi Sri. (7) Jangan memperjualbelikan labu dan singkong. Hal ini karena labu dan singkong sama halnya dengan padi, di tanam di tanah, seasal dengan manusia dari saripati tanah. (8) Jangan keluar rumah di malam hari dan pergi ke hutan sendiran. Kepercayaan ini berkaitan dengan sandekala yang dianggap sebagai monster yang dapat menggangu manusia.

\section{REFERENSI}

Adimihardja, Kusnaka. 1992. Kasepuhan yang Tumbuh di atas yang Luhur. Bandung: Tarsito.

Danadibrata. 2006. Kamus Basa Sunda. Bandung: Kiblat Buku Utama.

Dwiyanti, R., \& Suherman, A. (2019). Unsur Budaya Dalam Cerita Film Cakra Buana Karya Sutradara Massimo Burhanuddin. LOKABASA, 10(2), 204213.

Hafid, Ahmad. 2013. Sistem Kepercayaan Pada Komunitas Adat Kajang Desa Tanah Towa Kecamatan Kajang Kabupaten Bulukumba. Patanjala, 5(1).

Koentjaraningrat. 1996. Pengantar Antropologi I. Jakarta: Rineka Cipta.

Koentjaraningrat. 2002. Pengantar Antropologi Pokok-Pokok Etnografi II. Jakarta: Rineka Cipta.

Koentjaraningrat. 2009. Pengantar Ilmu Antropologi. Jakarta: Rineka Cipta.

Maryaeni. (2005). Metode Penelilian Kebudayaan. Jakarta: Burni Aksara.

Mufid, Ahmad Syafii. 2012. Dinamika Perkembangan Sistem Kepercayaan Lokal di Indonesia. Jakarta: Kementrian Agama RI Badan Litbang dan Diklat Puslitbang Kehidupan Keagamaan.

Satjadibrata, R. 2005. Kamus Basa Sunda. Bandung: Kiblat. 
Suherman, A. (2018). Jabar Masagi: Penguatan Karakter Bagi Generasi Milenial Berbasis Kearifan Lokal. Lokabasa, 9(2), 107.

Suherman, A. (2019). Literacy Tradition of Sundanese Society-Indonesia.

International Journal for Innovation Education and Research, 7(3), 262-271. https://doi.org/10.31686/ijier.Vol7.Iss3.13 77.

Sumardjo, Jakob. 2011. Sunda Pola Rasionalitas Budaya. Bandung: Kelir.

Soelaeman. 2010. Ilmu Budaya Dasar. Bandung: Refika Aditama.

Wulansari, Dewi. 2009. Sosiologi Konsep dan Teori. Bandung: Refika Aditama. 